\title{
The Effects of Talent Management on Service Quality: A Study on Commercial Banks in Egypt
}

\author{
Wageeh Nafei ${ }^{1}$ \\ ${ }^{1}$ University of Sadat City, Menoufia, Egypt \\ Correspondence: Wageeh Nafei, University of Sadat City, Menoufia, Egypt. E-mail: dr.wageeh1965@yahoo.com
}

Received: June 5, 2014

Accepted: November 20, 2014

Online Published: March 25, 2015

doi:10.5539/ibr.v8n4p41

URL: http://dx.doi.org/10.5539/ibr.v8n4p41

\begin{abstract}
Background: Talent Management (TM), as a new managerial concept with regard to Human Resource Management (HRM), has increasingly gained concern and attention from the academic as well as business world, but there are many gaps left for further theoretical development and empirical study. On the other hand, Service Quality (SQ) has become a popular area of academic research.
\end{abstract}

Purpose: The purpose of this study is to investigate the relationships between TM and SQ at the Egyptian Commercial Banks (ECB).

Research Design/Methodology: Using Heinen \& O'Neill (2004) of TM, the study develops a number of hypotheses and tests them. This research is an applied form in terms of its goals and is descriptive in terms of the method of data collection. Of the 382 questionnaires that were distributed, 300 usable questionnaires were returned, a response rate of $78 \%$.

Findings: The main findings are that for TM significantly and positively related to the SQ. In other words, TM are more effective in achieving SQ. High TM will be more likely to achieve high profit.

Practical implications: The study suggests that the ECB can improve SQ by influencing its TM. The study provided that the necessity to pay more attention to the dimensions of TM as a key source for organizations to enhance the competitive advantage which is of prime significance for SQ.

Originality/value: The study observes that there is a critical shortage of TM and that a greater understanding of the factors that influence the SQ is of great importance. Therefore, this study is to examine the relationship between TM and SQ at the ECB.

Keywords: talent management, service quality

\section{Introduction}

The War for Talent, was first used by some McKinsey consultants (Axelrod et al., 2002). Since then, TM has been regarded as a means for tackling HR challenges (Ritz \& Sinelli, 2010).

There is a lack of empirical research regarding TM area. It is a recent notion in the field. Therefore, many larger organizations have had introduced methods and procedures for working with TM, and it can be a relevant source for funding different tactics (Höglund, 2012).

TM is the most important factor in ensuring sustainable organizational success. The Boston Consulting Group \& World Federation of People Management Associations found that the three most important areas were TM, leadership development and performance management and rewards (McDonnell, 2011).

All organizations must tackle the needs of their talented people and have a fully integrated system (Clark, 2010). Whether TM is called people, intellectual capital, HR, talent or some other term, the resource that lies within employees and how they are organized is increasingly recognized as critical to strategic success and competitive advantage (Boudreau \& Ramstad, 2007).

The future of TM draws on bottom-up theories focusing on core business functionality which is based on unified TM. TM has three main traits: (1) talent is bulwark of any organization, (2) the trait of your staff is your major distinct factor of completion, and (3) performance is boosted by talent (Shukla, 2009). 


\section{Literature Review}

\subsection{Definitions of Talent}

The definition of talent differs, from focusing on certain individuals in an organization, having a certain number of characteristics that describe talent, to the concept referring to statements of need (Yarnall, 2011).

Talent is defined as natural aptitude or skill. Aptitude is a natural ability or inclination while skill is defined as the ability to do something well (Oxford Dictionary, 2012).

In ancient Syria, Babylonia, Greece and the Roman Empire, the word talent was a denomination of weight, and later surfaced in the Bible as a monetary unit. As of the medieval ages, the word talent developed into the word as we know it today, referring to natural ability and aptitudes. Nowadays in our modern European languages, talent refers to an innate giftedness, which is regarded as a gift (Tansley, 2011).

Talent is a resource that includes the potential and realized capacities of individuals and groups and how they are organized, including those within the organization and those who might join the organization (Boudreau \& Ramstad, 2007). It consists of those individuals who can make a difference to organizational performance, either through their immediate contribution or in the longer term by demonstrating the highest levels of potential (Tansley et al., 2007).

It is the primary driver of any successful company. It's become increasingly obvious to most business owners and executive teams that, rather than being constrained by capital, companies are typically most constrained by talent. Corporations have learned that, depending on what your business strategy is and what challenges you may face, at any given time you need the right talent to execute that strategy or deal with that challenge (Gebelein, 2006).

Talent is sometimes described as an elite group of people within an organization (Coleman, 2005). Talent not only has become more important among all the factors that could influence the effectiveness of organizations in the future (Buckingham \& Vosburgh, 2001), but also remains in limited supply (Frank et al., 2004).

It is the sum of a person's abilities, including intrinsic gifts, skills, knowledge, intelligence, attitude, drive and the ability to learn (Cartwright, 2003).

It also incorporates the individual's ability to learn and grow (Michaels et al., 2001). Talent is the most important corporate resource sophisticated business people who are technologically literate, globally astute, and operationally agile (Fishman, 1998).

\subsection{Talent Management}

TM indicates a move back to organizations taking more control of the career of the high potential employees (Yarnall, 2011).

There are three stream regarding TM A first stream emphasizes the human capital, a second stream sees TM as a process through which employers anticipate and meet their needs for human capital, and a third stream perceives it as a means for attaining economic ends (Silzer \& Dowell, 2010). TM includes the sourcing, screening, selection, development, deployment and renewal of the workforce (Brewster et al., 2010).

TM is a tool for achieving increased profits (Becker et al., 2009). The criteria of talents are that they are valuable, rare, and hard-to-imitate (Hughes \& Rog, 2008).

The importance of TM is due to the following facts (1) employees preserve experience, (2) TM boosts progress, (3) it is depended on individuals, (4) it is employed by individuals (Nelson \& McCann, 2008).

It is the additional management processes and opportunities that are made available to people in the organization who are considered to be talent (Blass, 2007). TM means full capitalization of valuable individuals (CIPD, 2007).

There are three trends in TM. They are (1) TM is conceptualized in terms of typical HR department practices, functions and activities, (2) TM is defined in terms of HR planning and projecting employee needs and (3) TM is treated as a generic entity and either focuses on high performing and high potential talent or on talent in general (Lewis \& Heckman, 2006). TM selects the suitable person in the his or her suitable job at the right time (Lewis \& Heckman, 2006).

TM refers to a continuous process of external recruitment and selection and internal development and retention. (Knez et al., 2004).

TM can be defined as ensuring that a sufficient supply of talent is available across the organization to achieve 
competitive advantage, enhanced corporate performance, and maximizing the productivity of an organization's talent pool (Newhouse et al., 2004).

TM refers to the core employees and leaders that drive the business forward. They are the top achievers and the ones inspiring others to superior performance. Talent employees represent the core competence of the organization and comprise a small percentage of the employees (Berger \& Berger, 2003).

TM represents a paradigm shift from more traditional HR related sources of competitive advantage literature such as those that focus on organizational elites, including upper echelon literature, and strategic HRM towards the management of talent specifically suited to today's dynamic competitive environment (Huselid et al., 1997; Miller et al., 1998). In this research, TM is used to describe the additional practices that are aimed at the talented employees.

\subsection{TM Dimensions}

According to Heinen \& O'Neill (2004), TM process includes the following dimensions:

\subsubsection{TM Planning}

Talent planning means optimal capitalization of an organization's aptitudes. Thorough management must be used to attain TM strategy, attracting, motivating and retaining talented staff (Gakovic \& Yardley, 2007).

\subsubsection{Recruitment}

The processes of finding the recruitment strategy are (1) stating the key business objectives for the next five to ten years, (2) determining the skills and talent necessary to accomplish the strategic goals, and (3) deciding whether the current workforce has the skills necessary, and whether to develop them. These steps are crucial to go through in order to understand the available resources within the organization before deciding whether to recruit or not (Vaiman \& Vance, 2008).

Recruitment means having a host of qualified candidates for a job by selecting top university graduates (Gomez-Mejia et al., 2004).

\subsubsection{Compensation and Rewards}

To keep valued employees, TM compensation and rewards are highly recommended because employees value incentives and bonus schemes. Less working hours, access to conferences and short courses are more incentive (Richman et al., 2008).

Employees have more commitment to an organization in case of having life insurance, disability insurance and flexible hours (Kirkland, 2009). Coetsee (2004) affirms the importance of rewards for worthy employees for them to exert more efforts.

\subsubsection{Performance Management}

Performance management (PM) is a continuous process of identifying, measuring and developing the performance of individuals and teams and aligning performance with the strategic goals of the organization (Aguinis et al., 2012).

PM is about how to create, control and measure a culture of performance, where the system should control that the employee does the right things, not things right. The characteristic of successful enterprises is that they cascade their goals (Wikström \& Martin, 2012).

PM has five major dimensions (1) the vision, strategies, and goals of the organization, agree with staff member's personal goals and objectives, (2) personnel's goals and goals of the organization agree, (3) performance benchmarks should be based on the value proposition, (4) we must be able to determine, measure, and realize goals which should be practical and time limited, and (5) performance should be evaluated to decide how far it agrees with goals (Coetsee, 2004).

Revising performance is pivotal to TM as it clarifies the reward system, succession plans and staff development, helps estimate powers of the workforce and gives feedback to the employee (DuBrin, 2005).

\subsubsection{Employee Empowerment}

Empowerment means delegation of authority and responsibility from managers to staff. Taking part in management and decision making may be a sort of empowerment (DuBrin, 2010). Empowerment needs commitment of managers to train staff and provide job requirements (Gomez-Mejia et al., 2004). 


\subsubsection{Employee Engagement}

Employee engagement and sense of belonging highly boosts organizational performance. They decide their role in the organization (Kennedy \& Daim, 2010).

Employee engagement is a psychological state within which an employee connects and identifies at a personal level with their job and organization, resulting in retention and improved performance (Kock \& McNamara, 2009). Employee engagement is the heightened emotional and intellectual connection that an employee has for his/her job, organization, manager, or co-workers that, in turn, influence him/her to apply additional discretionary effort to his/her work (Richman et al., 2008).

The engaged workers exert maximum performance, realize more retention, less absenteeism and more customer satisfaction (Wagner, 2006).

The major requirements of employee engagement include: the job itself, opportunities, quality of life, procedures and HR policies, the quality of the supervision, freedom of expression by employees, talent and skill utilization, and satisfied employees know what is expected (Schaufeli \& Bakker, 2002).

\subsubsection{Organizational Culture}

OC of an organization implies its tenets and mores (Coetsee, 2004). A positive culture helps employees stay with the organization. Understanding corporate culture and using it as a retention strategy has become the subject of much research (Phillips \& Connell, 2003).

Managers are the living, breathing embodiment of the culture of the organization. It is important that the messages they are sending are aligned with the overall corporate culture (Ahlrichs, 2003).

\subsection{Service Quality}

Quality was seen as a defensive mechanism but it is seen as a competitive weapon for emergence of new markets as well as growing market share (Davis et al., 2003). It refers to the matching between what customers expect and what they experience (Berry et al., 1988).

SQ is the overall assessment of a service by the customers (Eshghi et al., 2008). SQ is the difference between customer's expectations for the service encounter and the perceptions of the service received (Munusamy et al., 2010).

SQ is the result of the comparison that customers make between their expectations about a service and their perception of the way the service has been performed (Caruana, 2002).

SQ has become a popular area of academic research and has been acknowledged as an observant competitive advantage and supporting satisfying relationships with customers (Zeithmal, 2000).

SQ is the customer perception of how does a service meets or exceeds their expectations (Czepiel, 1990). SQ is interpreted as perceived quality which means a customer's judgment about a service. SQ is the degree of discrepancy between customers' normative expectation for service and their perceptions of service performance (Parasuraman et al., 1985).

SQ was developed as the overall evaluation of a specific service firm that results from comparing that firm's performance with the customer's general expectations of how firms in that industry should perform (Parasuraman et al., 1988).

SERVQUAL (Service Quality) which has been extensively used in assessing SQ of different service providers including banks suggested that quality evaluations are not made solely on the outcome of a service; they also involve evaluations of the process of service delivery. According to SERVQUAL model, SQ is defined as the gap between customer perceptions of what happened during the service transaction and his expectations of how the service transaction should have been performed (Parasuraman et al., 1985).

Although there has been criticism from some other researchers to SERVQUAL instrument (Johnston, 1995), yet SERVQUAL is the instrument most utilized for its confirmatory factor analyses in most cases (Lymperopoulos et al., 2006).

The SERVPERF model was carved out of SERVQUAL by Cronin and Taylor in 1992. SERVPERF measures SQ by using the perceptions of customers. Cronin and Taylor argued that only perception was sufficient for measuring SQ and therefore expectations should not be included as suggested by SERVQUAL (Baumann, 2007).

\subsection{Service Quality Dimensions}

The SERVQUAL model proposed a five dimensional construct of perceived SQ (1) reliability (delivering the 
promised outputs at the stated level), (2) responsiveness (providing prompt service and help to customers; the reaction speed plays a vital role here), (3) assurance (ability of a service firm to inspire trust and confidence in the firm through knowledge, politeness and trustworthiness of the employees), (4) empathy (willingness and capability to give personalized attention to a customer), and (5) tangibles (appearance of a service firm's facilities, employees, equipment and communication materials) (Parasuramanet el al., 1988).

\subsubsection{Reliability}

Reliability depends on handling customers' services problems; performing services right the first time; provide services at the promised time and maintaining error-free record (Parasuraman et al., 1988).

\subsubsection{Responsiveness}

Responsiveness is defined as the willingness or readiness of employees to provide service. It involves timeliness of services (Parasuraman et al., 1985).

It is involves understanding needs and wants of the customers, convenient operating hours, individual attention given by the staff, attention to problems and customers" safety in their transaction (Kumar et al., 2009).

\subsubsection{Empathy}

Empathy is the caring and individual attention the firm provides its customers. It involves giving customers individual attention and employees who understand the needs of their customers and convenience business hours (Parasuraman et al., 1985).

Empathy is giving individual attention; convenient operating hours; giving personal attention; best interest in heart and understand customer's specific needs (Ananth et al., 2011).

\subsubsection{Assurance}

Assurance as knowledge and courtesy of employees and their ability to inspire trust and confidence (Parasuraman et al., 1985).

Assurance means the polite and friendly staff, provision of financial advice, interior comfort, eases of access to account information and knowledgeable and experienced management team (Sadek et al., 2010).

\subsubsection{Tangibility}

Tangibility signifies the outlook of concrete utilities, devices, workers, and paper works (Parasuraman et al., 1985).

Tangibility is the modern looking equipment, physical facility, employees are well dressed and materials are visually appealing (Ananth et al., 2011).

\section{Research Model}

The diagram below shows that there is one independent variable TM. There is one dependent variable of the SQ.

The conceptual model can be set up as shown in the following figure.

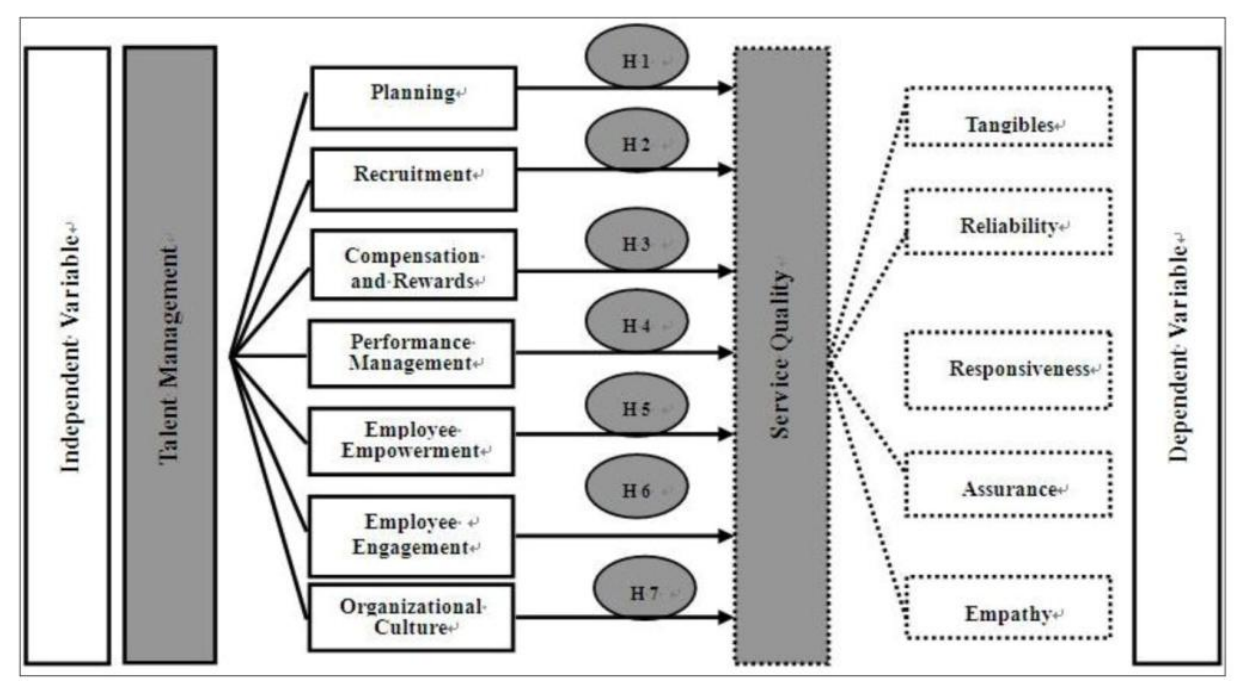

Figure 1. Proposed comprehensive conceptual model 
The research framework suggests that TM have an impact on SQ. TM as measured consists of planning, recruitment, compensation and rewards, performance management, employee empowerment, employee engagement, and OC (Heinen \& O'Neill, 2004). SQ is measured in terms of tangibles, reliability, responsiveness, assurance, and empathy (Parasurman et al., 1988; and Cronin \& Taylor, 1992).

\section{Research Questions}

The researcher found the research problem through two sources. The first source is to be found in previous studies, and it turns out that there is a lack in the number of literature review that dealt with the analysis of the relationship between TM and SQ at the ECB. This called for the researcher to test this relationship in the Egyptian environment. The second source is the pilot study, which was conducted an interview with (30) employees in the ECB in order to identify the dimensions of TM on the one hand, and SQ on the other. The researcher found through the pilot study several indicators notably the important and vital role that could be played by TM in improving SQ at the ECB. The attempt of this study was to answer the following questions:

Q1: What is the nature and the extent of the relationship between TM (planning) and SQ at the ECB.

Q2: What is the relationship between TM (recruitment) and SQ at the ECB?

Q3: What is the relationship between TM (compensation and rewards) and SQ at the ECB?.

Q4: What is the nature of the relationship between TM (performance management) and SQ at the ECB.

Q5: What is the extent of the relationship between TM (employee empowerment) and SQ at the ECB.

Q6: What is the nature of the relationship between TM (employee engagement) and SQ at the ECB.

Q7: What is the employees' perception towards TM (organizational culture) and SQ at the ECB.

\section{Research Hypotheses}

The effective TM of staff are widely recognized as key to the effective service delivery and customer satisfaction (Gracia et al., 2013; Osman et al., 2011; Popescu et al., 2012).

SQ is defined by the relationship between the expectations of customers and how they perceive their experience. SQ can be measured in terms of five main dimensions namely tangibles, assurance, responsiveness, reliability and empathy (Parasuraman et al., 1988).

Schneider et al. (1998) maintain that employees can only deliver a quality service if the organization supports them through resources, training, management practices, and assistance.

In particular talent practices such as skills training, competence development, career development plans and sound performance appraisal systems are key to the enhancement of SQ (Osman et al., 2011; Popescu et al., 2012).

Other researchers also highlighted talent attraction and retention practices as an important determinant of quality service delivery (Scott \& Revis, 2008; Zheng, 2009).

From the above statement, this study attempts to test the following hypotheses:

H1: Employees' perception of TM (planning) has no significant effect on SQ at the ECB.

H2: There is no statistically significant relationship between TM (recruitment) and SQ at the ECB.

H3: TM (compensation and rewards) does not have an impact on SQ at the ECB.

H4: Employees' perception of TM (performance management) has no significant effect on SQ at the ECB.

H5: TM (employee empowerment) is not positively correlated with SQ at the ECB.

H6: TM (employee engagement) has no significant effect on SQ at the ECB.

H7: There is no statistically significant relationship between TM (organizational culture) and SQ at the ECB.

\section{Research Methods}

\subsection{Population and Sample}

The study subjects are employees at the ECB. The total population is 66536 employees. Determination of respondent sample size was calculated using the formula (Daniel, 1999):

$$
\frac{N \times(Z)^{2} \times P(1-P)}{d^{2}(N-1)+(Z)^{2} \times P(1-P)}
$$

The number of samples obtained by 382 employees at the ECB is presented in Table 1 . 
Table 1. Distribution of the sample size

\begin{tabular}{ccccc}
\hline Bank Type & Number of Population & Percentage & \multicolumn{2}{c}{ Sample Size } \\
\hline General Commercial Banks & 52564 & $79 \%$ & $382 \times 79 \%=302$ \\
Joint Commercial Banks & 11977 & $18 \%$ & $382 \times 18 \%=69$ \\
Foreign Branches of Banks & 1995 & $3 \%$ & $382 \times \quad 3 \%=11$ \\
Total & $\mathbf{6 6 5 3 6}$ & $\mathbf{1 0 0 \%}$ & $\mathbf{3 8 2} \times \mathbf{1 0 0 \%}=\mathbf{3 8 2}$ \\
\hline
\end{tabular}

Source: Central Bank of Egypt, Economic Magazine, 2012.

\subsection{Method of Data Collection}

The goal of this study was to examine the relationships between TM and SQ at the ECB. A survey research method was used to collect data. The questionnaire included three questions, relating to TM, SQ, and demographic data of employees at the ECB. The study subjects are full-time employees at the ECB. A total of 382 questionnaires were sent out. The number of effective questionnaires was 300 (78\% valid questionnaire collection rate).

Table 2. Sample distribution

\begin{tabular}{|c|c|c|c|}
\hline Variables & Classification & Number & Percentage \\
\hline \multirow{9}{*}{ 1- Job Title } & General Manager & 20 & $6.7 \%$ \\
\hline & Deputy General Manager & 20 & $6.7 \%$ \\
\hline & Agent General Manager & 20 & $6.7 \%$ \\
\hline & Deputy Manager & 35 & $11.7 \%$ \\
\hline & Controller & 35 & $11.7 \%$ \\
\hline & Excellent Banker & 45 & $15.0 \%$ \\
\hline & Banker A & 43 & $14.3 \%$ \\
\hline & Banker B & 82 & $27.3 \%$ \\
\hline & Total & 300 & $100 \%$ \\
\hline \multirow{3}{*}{ 2- Marital Status } & Married & 207 & $69.0 \%$ \\
\hline & Single & 193 & $31.0 \%$ \\
\hline & Total & 300 & $100 \%$ \\
\hline \multirow{4}{*}{ 3- Age } & Less than 30 years & 122 & $40.7 \%$ \\
\hline & From 30 to 45 & 135 & $45.0 \%$ \\
\hline & More than 45 & 43 & $14.3 \%$ \\
\hline & Total & 300 & $100 \%$ \\
\hline \multirow{2}{*}{ 4- Educational Level } & Secondary School & 165 & $55.0 \%$ \\
\hline & University Education & 135 & $45.0 \%$ \\
\hline \multirow{5}{*}{ 5- Period of Experience } & Total & 300 & $100 \%$ \\
\hline & Less than 5 years & 62 & $20.7 \%$ \\
\hline & From 5 to 10 & 205 & $68.3 \%$ \\
\hline & More than 10 & 33 & $11.0 \%$ \\
\hline & Total & 300 & $100 \%$ \\
\hline
\end{tabular}

\subsection{Research Variables and Methods of Measuring}

This research studied the relationship between TM and SQ. The 55-item scale TM section is based on Heinen \& O'Neill (2004). There were six items measuring talent planning, eight items measuring recruitment, eleven items measuring compensation and rewards, seven items measuring PM, five items measuring employee 
empowerment, eleven items measuring employee engagement, and seven items measuring OC.

The 25-item scale SQ section is based on Parasuramanet el al. (1988). Aspects of SQ include reliability, responsiveness, assurance, empathy, and tangibles. The 25 statements equally divided among secondary measures.

Responses to all items scales were anchored on a five (5) point Likert scale for each statement which ranges from (5) "full agreement," (4) for "agree," (3) for "neutral," (2) for “disagree," and (1) for "full disagreement."

\subsection{Methods of Data Analysis and Testing Hypotheses}

The researcher has employed the following methods: (1) The Alpha Correlation Coefficient (ACC), (2) Multiple Regression Analysis (MRA), and (3) F- test and T-test.

\section{Hypotheses Testing}

Before testing the hypotheses and research questions, descriptive statistics were performed to find out means and standard deviations of TM and SQ.

Table 3. The mean and standard deviations of TM and SQ

\begin{tabular}{|c|c|c|c|}
\hline Variables & The Dimension & Mean & Standard Deviation \\
\hline \multirow{8}{*}{$\mathbf{T M}$} & Talent Planning & 4.0672 & 0.85757 \\
\hline & Recruitment & 3.9242 & 0.88688 \\
\hline & Compensation and Rewards & 4.0958 & 0.64589 \\
\hline & Performance Management & 4.1019 & 0.53944 \\
\hline & Employee Empowerment & 3.1320 & 1.35781 \\
\hline & Employee Engagement & 3.9691 & 0.79686 \\
\hline & Organizational Culture & 4.6167 & 0.39989 \\
\hline & Total Measurement & 4.0218 & 0.66158 \\
\hline \multirow{6}{*}{ SQ } & Tangibles & 4.3807 & 0.71918 \\
\hline & Reliability & 3.6680 & 0.99519 \\
\hline & Responsiveness & 4.1773 & 0.92762 \\
\hline & Assurance & 3.6933 & 1.00811 \\
\hline & Empathy & 4.2047 & 0.93771 \\
\hline & Total Measurement & 4.0248 & 0.6997 \\
\hline
\end{tabular}

Table 3 lists the mean, and standard deviation among variables. The mean of each variable is more than 3, and this result indicates that the study subjects have a higher level of TM and SQ. The different facets of TM are examined. Most respondents identified the presence of OC $(\mathrm{M}=4.61, \mathrm{SD}=0.399)$. This was followed by performance management $(\mathrm{M}=4.10, \mathrm{SD}=0.539)$, compensation and rewards $(\mathrm{M}=4.09, \mathrm{SD}=0.645)$, talent planning $(\mathrm{M}=4.06, \mathrm{SD}=0.857)$, employee engagement $(\mathrm{M}=3.96, \mathrm{SD}=0.796)$, recruitment $(\mathrm{M}=3.92, \mathrm{SD}=0.886)$ and employee empowerment $(\mathrm{M}=3.13, \mathrm{SD}=1.357)$.

The different facets of SQ are examined. Most respondents identified the presence of tangibles $(\mathrm{M}=4.38$, $\mathrm{SD}=0.719)$. This was followed by empathy $(\mathrm{M}=4.20, \mathrm{SD}=0.937)$, responsiveness $(\mathrm{M}=4.17, \mathrm{SD}=0.927)$, assurance $(\mathrm{M}=3.69, \mathrm{SD}=1.008)$ and reliability $(\mathrm{M}=3.66, \mathrm{SD}=0.995)$.

\subsection{Evaluating Reliability}

ACC was used to evaluate the degree of internal consistency among the contents of the scale under testing. It was decided to exclude variables that had a correlation coefficient of less than 0.30 when the acceptable limits of ACC range from 0.60 to 0.80 , in accordance with levels of reliability analysis in social sciences (Nunnally \& Bernstein, 1994).

To assess the reliability of the data, Cronbach's alpha test was conducted. Table 4 shows the reliability results for TM and SQ. All items had alphas above 0.60 and were therefore excellent, according to Langdridge's (2004) criteria. 
The 55 items of OC are reliable because the ACC is 0.9644 . The 6 items of talent planning are reliable due to the fact that the ACC is 0.8162 . The recruitment, which consists of 8 items, is reliable since the ACC is 0.8605 . The 11 items related to compensation and rewards are reliable as ACC is 0.8287. Furthermore, the performance management, which consists of 7 items, is reliable due to the fact that the ACC is 0.6192 . The 5 items of employee empowerment are reliable due to the fact that the ACC is 0.9130 . The employee engagement, which consists of 11 items, is reliable since the ACC is 0.8790 . The 7 items related to OC are reliable as ACC is 0.8098 .

Table 4. Reliability of TM and SQ

\begin{tabular}{clcc}
\hline \multicolumn{1}{c}{ The Dimension } & Number of Statement & ACC \\
\hline & Talent Planning & 6 & 0.8162 \\
& Recruitment & 8 & 0.8605 \\
& Compensation and Rewards & 11 & 0.8287 \\
TM & Performance Management & 7 & 0.6192 \\
& Employee Empowerment & 5 & 0.9130 \\
& Employee Engagement & 5 & 0.8790 \\
& Organizational Culture & 11 & 0.8098 \\
& Total Measurement & 7 & $\mathbf{0 . 9 6 4 4}$ \\
& Tangibles & 55 & 0.6151 \\
& Reliability & 5 & 0.8236 \\
& Responsiveness & 5 & 0.8650 \\
& Assurance & 5 & 0.8247 \\
& Empathy & 5 & 0.8653 \\
& Total Measurement & 5 & $\mathbf{0 . 9 1 5 6}$ \\
\hline
\end{tabular}

The 25 items of SQ are reliable due to the fact that the ACC is 0.9156 . The reliability, which consists of 5 items, is reliable since the ACC is 0.8236 while the 5 items related to responsiveness is reliable as the ACC is 0.8650 . Furthermore, the assurance, which consists of 5 items, is reliable due to the fact that the ACC is 0.8247 . The 5 items of empathy are reliable due to the fact that the ACC is 0.8653 . The tangibles, which consists of 5 items, is reliable since the ACC is 0.6151 .

\subsection{The Relationship between TM (Planning) and $S Q$}

Table 5. MRA results for TM (planning) and SQ

\begin{tabular}{|c|c|c|c|}
\hline The Variables of TM (Planning) & Beta & $\mathrm{R}$ & $\mathrm{R}^{2}$ \\
\hline 1. TM is vital in the strategic plan of ECB & $0.259^{* *}$ & $0.303^{* *}$ & 0.091 \\
\hline 2. ECB regularly analyses talent needs & $0.223^{* *}$ & $0.158^{* *}$ & 0.024 \\
\hline 3. ECB has a clear TM strategy & $0.273^{* *}$ & $0.743^{* *}$ & 0.552 \\
\hline 4. All management positions are included in a scheme of replacing jobs outlined by ECB & $0.103^{* *}$ & $0.721^{* *}$ & 0.519 \\
\hline 5. Candidates have access to internet-based data outlined by ECB & $0.335^{* *}$ & $0.767^{* *}$ & 0.588 \\
\hline 6. ECB TM strategy primarily sources talent from outside the organization. & $0.276^{* *}$ & $0.660^{* *}$ & 0.435 \\
\hline - Multiple Correlation Coefficients (MCC) & & 0.872 & \\
\hline - Determination of Coefficient (DF) & & 0.760 & \\
\hline - The Value of Calculated F & & 154.459 & \\
\hline - Degree of Freedom & & 6,293 & \\
\hline - The Value of Indexed F & & 2.80 & \\
\hline - Level of Significant & & 0.01 & \\
\hline
\end{tabular}


According to Table 5, the regression-coefficient between TM (Planning) and SQ is $\mathrm{R}=0.872$ and $\mathrm{R}^{2}=0.760$. This means that the SQ can be explained by the dimensions of TM (Planning).

Because of the calculated F (154.459) more than indexed F (2.80) at the statistical significance level of 0.01, the null hypotheses is rejected.

\subsection{The Relationship between TM (Recruitment) and $S Q$}

Table 6. The relationship between TM (recruitment) and SQ

\begin{tabular}{|c|c|c|c|}
\hline The Variables of TM (Recruitment) & Beta & $\mathrm{R}$ & $\mathrm{R}^{2}$ \\
\hline 1. ECB advertises an interesting host of benefits for employees & $0.315^{* *}$ & $0.735^{* *}$ & 0.054 \\
\hline 2. Gabs may be revised by a meticulous audit & 0.006 & $0.242^{* *}$ & 0.058 \\
\hline 3. Talents are widely selected through recruitment & $0.186^{* *}$ & $0.314^{* *}$ & 0.098 \\
\hline 4. Internal talents are preferred for new jobs & $0.165^{* *}$ & $0.173^{* *}$ & 0.029 \\
\hline 5. New employees make use of induction programs & $0.212^{* *}$ & $0.727^{* *}$ & 0.528 \\
\hline 6. ECB enjoy many talented managers for new jobs & $0.585^{* *}$ & $0.743^{* *}$ & 0.552 \\
\hline 7. ECB has a bundle of talented managers & $0.269^{* *}$ & $0.718^{* *}$ & 0.515 \\
\hline 8. Outstanding talents get the jobs & $0.248^{* *}$ & $0.721^{* *}$ & 0.519 \\
\hline - Multiple Correlation Coefficients (MCC) & & 0.870 & \\
\hline - Determination of Coefficient (DF) & & 0.758 & \\
\hline - The Value of Calculated F & & 113.745 & \\
\hline - Degree of Freedom & & 8,291 & \\
\hline - The Value of Indexed F & & 2.51 & \\
\hline - Level of Significant & & 0.01 & \\
\hline
\end{tabular}

Note. $* \mathrm{P}<.05 ; * * \mathrm{P}<.01$.

According to Table 6, the regression-coefficient between TM (Recruitment) and SQ is $R=0.870$ and $\mathrm{R}^{2}=0.758$. This means that the SQ can be explained by the dimensions of TM (Recruitment). Thus, the null hypothesis is rejected because TM (Recruitment) and SQ have a statistical relationship at the significance level of 0.01 .

\subsection{The relationship between TM (Compensation) and $S Q$}

Table 7. The relationship between TM (compensation) and SQ

\begin{tabular}{|c|c|c|c|}
\hline The Variables of TM (Compensation) & Beta & $\mathrm{R}$ & $\mathrm{R}^{2}$ \\
\hline 1. My salary suits my level & 0.099 & $0.314^{* *}$ & 0.098 \\
\hline 2. My salary fits market requirements & $0.309^{* *}$ & $0.173^{* *}$ & 0.029 \\
\hline 3. The remuneration package is attractive & 0.017 & $0.327^{* *}$ & 0.106 \\
\hline 4. My wage encourages me not to leave ECB & 0.143 & $0.197^{* *}$ & 0.038 \\
\hline 5. My wage suits my work & 0.133 & 0.090 & 0.001 \\
\hline 6. Rewards urge me to do my utmost & 0.164 & $0.679^{* *}$ & 0.461 \\
\hline 7. In ECB, peter performance is the criterion for promotion & $0.474^{* *}$ & $0.727^{* *}$ & 0.528 \\
\hline 8. There are incentives for good performance & $0.673^{* *}$ & $0.718^{* *}$ & 0.515 \\
\hline 9. There are different types of rewards offered. & $0.097^{* *}$ & 0.048 & 0.001 \\
\hline 10. I perceive the reward system to be equitable & $0.153^{*}$ & $0.134^{*}$ & 0.019 \\
\hline 11. Rewards given for good performance are valuable & 0.046 & $0.702^{* *}$ & 0.492 \\
\hline - $\quad$ Multiple Correlation Coefficients (MCC) & & 0.844 & \\
\hline - Determination of Coefficient (DF) & & 0.712 & \\
\hline - The Value of Calculated F & & 64.882 & \\
\hline - Degree of Freedom & & 11,288 & \\
\hline - The Value of Indexed F & & 2.18 & \\
\hline - Level of Significant & & 0.01 & \\
\hline
\end{tabular}

Note. $* \mathrm{P}<.05 ; * * \mathrm{P}<.01$. 
According to Table 7, the regression-coefficient between TM (Compensation) and SQ is R=0.844 and R2= 0.712. This means that the SQ can be explained by the dimensions of TM (Compensation). Therefore, there is enough empirical evidence to reject the null hypothesis.

\subsection{The Relationship between TM (Performance) and $S Q$}

Table 8. The relationship between TM (performance) and SQ

\begin{tabular}{llcc}
\hline \multicolumn{1}{c}{ The Variables of TM (Performance) } & Beta & $\mathrm{R}$ & $\mathrm{R}^{2}$ \\
\hline 1. $\quad$ Staff members know their goals and dates & 0.032 & 0.037 & 0.001 \\
2. My abilities are revised according to my performance & $0.336^{* *}$ & $0.197^{* *}$ & 0.038 \\
3. I have access to my estimation & $0.133^{* *}$ & 0.048 & 0.001 \\
4. My supervisor is interested in my estimation & $0.346^{* *}$ & $0.138^{*}$ & 0.019 \\
5. Weak estimation entails training & 0.104 & 0.325 & 0.105 \\
6. My organization conducts performance reviews regularly & $0.684^{* *}$ & $0.734^{* *}$ & 0.538 \\
7. My own goals agree with business goals & $0.373^{* *}$ & $0.392^{* *}$ & 0.153 \\
- Multiple Correlation Coefficients (MCC) & 0.800 & 0.641 \\
- Determination of Coefficient (DF) & & 74.340 \\
- The Value of Calculated F & & 7,292 \\
- Degree of Freedom & & 2.63 \\
- The Value of Indexed F & & & 0.01 \\
\hline
\end{tabular}

Note. $* \mathrm{P}<.05 ; * * \mathrm{P}<.01$.

According to Table 8, the regression-coefficient between TM (Performance) and SQ is R=0.800 and R2=0.641. This means that the SQ can be explained by the dimensions of TM (Performance). Thus, the null hypothesis is rejected because TM (Performance) and SQ have a statistical relationship at the significance level of 0.01 .

7.6 The Relationship between TM (Empowerment) and $S Q$

Table 9. MRA results for TM (empowerment) and SQ

\begin{tabular}{|c|c|c|c|}
\hline The Variables of TM (Empowerment) & Beta & $\mathrm{R}$ & $\mathrm{R}^{2}$ \\
\hline 1. I take part in my performance objectives & $0.395^{*}$ & $0.495^{* *}$ & 0.245 \\
\hline 2. My manager takes part in specifying tasks & 0.092 & $0.582^{* *}$ & 0.338 \\
\hline 3. My manager gives me authority of decision making in my job & 0.305 & $0.474^{* *}$ & 0.224 \\
\hline 4. My manager gives my authority to devise new ideas & $0.624^{* *}$ & $0.752^{* *}$ & 0.565 \\
\hline 5. My tasks need the spirit of responsibility & 0.207 & $0.599^{* *}$ & 0.358 \\
\hline - Multiple Correlation Coefficients (MCC) & & 0.768 & \\
\hline - $\quad$ Determination of Coefficient (DF) & & 0.591 & \\
\hline - The Value of Calculated F & & 84.812 & \\
\hline - Degree of Freedom & & 5,294 & \\
\hline - $\quad$ The Value of Indexed F & & 3.01 & \\
\hline - Level of Significant & & 0.01 & \\
\hline
\end{tabular}

Note. $* \mathrm{P}<.05 ; * * \mathrm{P}<.01$

According to Table 9, the regression-coefficient between TM (Empowerment) and SQ is R=0.768 and $\mathrm{R}^{2}=0.591$. This means that the SQ can be explained by the dimensions of TM (Empowerment). Because of the calculated F (38.038) more than indexed F (3.01) at the statistical significance level of 0.01, the null hypotheses is rejected. 


\subsection{The Relationship between TM (Engagement) and $S Q$}

Table 10. The relationship between TM (engagement) and SQ

\begin{tabular}{|c|c|c|c|}
\hline The Variables of TM (Engagement) & Beta & $\mathrm{R}$ & $\mathrm{R}^{2}$ \\
\hline 1. I enjoy my job & 0.004 & 0.197 & 0.038 \\
\hline 2. My job schedule is flexible enough to attain other career-related tasks & $0.134^{* *}$ & 0.048 & 0.001 \\
\hline 3. I enjoy a friendly job climate & 0.056 & 0.138 & 0.019 \\
\hline 4. I relate very well with my manager & 0.166 & 0.733 & 0.537 \\
\hline 5. My manager values my contribution & 0.101 & 0.713 & 0.508 \\
\hline 6. My skills are beneficial for many tasks in my bank & $0.402^{* *}$ & 0.743 & 0.552 \\
\hline 7. ECB has clear goals to which I am committed & $0.270^{* *}$ & 0.721 & 0.519 \\
\hline 8. My job gives me satisfaction & $0.304^{* *}$ & 0.748 & 0.559 \\
\hline 9. My job is secure at ECB & $0.291^{* *}$ & 0.744 & 0.553 \\
\hline 10. My planned career progression is achievable at ECB & $0.098^{* *}$ & 0.352 & 0.123 \\
\hline 11. There is equal opportunity for promotion at ECB & 0.010 & 0.195 & 0.038 \\
\hline - Multiple Correlation Coefficients (MCC) & & 0.883 & \\
\hline - Determination of Coefficient (DF) & & 0.780 & \\
\hline - $\quad$ The Value of Calculated F & & 92.836 & \\
\hline - Degree of Freedom & & 11,288 & \\
\hline - The Value of Indexed F & & 2.18 & \\
\hline - Level of Significant & & 0.01 & \\
\hline
\end{tabular}

Note. $* \mathrm{P}<.05 ; * * \mathrm{P}<.01$.

According to Table 10, the regression-coefficient between TM (Engagement) and SQ is R=0.883 and $\mathrm{R}^{2}=0.780$. This means that the SQ can be explained by the dimensions of TM (Engagement).

Thus, the null hypothesis is rejected because TM (Engagement) and SQ have a statistical relationship at the significance level of 0.01 .

\subsection{The Relationship between TM (Cultural) and $S Q$}

Table 11. The relationship between TM (cultural) and SQ

\begin{tabular}{|c|c|c|c|}
\hline The Variables of TM (Cultural) & Beta & $\mathrm{R}$ & $\mathrm{R}^{2}$ \\
\hline 1. I fully understand the $\mathrm{OC}$ of ECB and apply that as a guide in my job & 0.005 & 0.050 & 0.001 \\
\hline 2. Management communicates and lives the $\mathrm{OC}$ at $\mathrm{ECB}$ & $0.251^{* *}$ & 0.264 & 0.069 \\
\hline 3. ECB helps creativeness thanks to its culture & 0.113 & 0.017 & 0.001 \\
\hline 4. We do our utmost to avoid errors & $0.533^{* *}$ & 0.340 & 0.115 \\
\hline 5. Customers are satisfied thanks to ECB interactive culture & 0.170 & 0.179 & 0.032 \\
\hline 6. ECB employees are social interactive thanks to its culture & 0.162 & 0.182 & 0.033 \\
\hline 7. Services are better thanks to ECB culture & 0.106 & 0.132 & 0.017 \\
\hline - $\quad$ Multiple Correlation Coefficients (MCC) & & 0.451 & \\
\hline - Determination of Coefficient (DF) & & 0.204 & \\
\hline - $\quad$ The Value of Calculated F & & 10.661 & \\
\hline - Degree of Freedom & & 7, 292 & \\
\hline - The Value of Indexed F & & 2.63 & \\
\hline - Level of Significant & & 0.01 & \\
\hline
\end{tabular}

Note. $* \mathrm{P}<.05 ; * * \mathrm{P}<.01$. 
According to Table 11, the regression-coefficient between TM (Cultural) and SQ is $\mathrm{R}=0.451$ and $\mathrm{R} 2=0.204$. This means that the SQ can be explained by the dimensions of TM (Cultural). Therefore, there is enough empirical evidence to reject the null hypothesis.

\section{Research Findings}

Our findings support the view that the dimensions of TM (planning, recruitment, compensation and rewards, performance management, employee empowerment, employee engagement, and OC) were positively related with SQ.

The results support the view that TM significantly and positively influences SQ. This is consistent with the finding that the employees who believed their banks had TM were high SQ. The findings reveal that the TM was positively related with SQ. Overall findings from this study suggested that TM does affect SQ. Hence management should encourage an innovative supportive culture and conduct self evaluation exercises for each business unit so that shortcomings in customer service are addressed and mistakes are rectified.

Our findings support the view that more TM are more effective in achieving SQ. High TM will be more likely to achieve high profit. The results are important to enable bank managers to have a better understanding of customers' perception of SQ of banking and consequently of how to improve their satisfaction with respect to aspects of SQ. Owing to the increasing competition in banking, customer service is an important part and bank managers should be rethinking how to improve customer satisfaction with respect to SQ.

This result is consistent with a study by Gracia et al. (2013), which concluded that the TM significantly associated with SQ. Another study carried out by Osman et al. (2011), concluded that the TM directly affects the SQ. There is also another study carried out by Popescu et al. (2012) and concluded that the TM is positively correlated with SQ. Another study carried by Schneider et al. (1998); Scott and Revis (2008); Zheng (2009) found that there is a positive relationship between TM and SQ.

\section{Recommendations}

This study revealed that TM has become pivotal to the profit organization. ECB should take to cognizance the issue of TM. TM is an issue of import to modern management and government especially in developing nations. ECB should train and retrain their work force to develop needed talent in the staff. The correlation between profitability and TM cannot be overemphasized. It was therefore recommended that:

- TM should be used for all categories of staff within the ECB that have special talent.

- ECB should separate their TM scheme and the total HRM style of the bank.

- TM should be result oriented and not another HRM style without result in focus.

- The government in the developing nations, especially, should take the issue of TM very seriously in their economics policy from time to time; a pure capitalist economy must be practiced with caution.

- Every bank needs to align their TM system to their specific business requirements. There is no one way to do TM.

- When considering the right TM system for your bank, you first need to decide which perspective is most relevant to your business goals. It is then important to look at the most relevant dimensions to help shape the way you define, develop and structure your TM system.

- Designing and implementing a TM system can be shaped by the dimensions. All the case study banks could be mapped against these dimensions demonstrating that they are common to all TM systems.

- TM requires a talent culture to be developed so that talent conversations become acceptable throughout the bank and individuals are encouraged to expand their networks.

- TM systems can complement diversity initiatives by ensuring equality of opportunity to enter the talent pool and transparency over selection criteria.

- When designing appropriate routes for developing talent within your bank, it is important to consider the prevailing culture within your bank and the appetite for risk.

- TM is important to achieve alignment with the organization's strategic objectives.

- It is important that any TM system is integrated across all aspects of HRM. There are clear inter-dependencies between TM and recruitment, development, retention and succession planning practices.

- TM strategy must be taken seriously into account. ECB should analyze talent and communicate the TM strategy to employees. ECB should have succession plan 
- The bank should detect skills and decide if they agree with the business strategy. Besides, TM develops career planning. It should be integrating with HRM.

\section{Research Implications}

\subsection{Academic Implications}

Literature reviews of TM bring up the fact that there is no agreed upon explanation of what TM is. There is a disturbing lack of clarity regarding the definition, scope and overall goals of TM. There are recurring ideas concerning the meaning of TM. The first defines TM as a collection of typical HR department practices. The second idea is about talent pools, and how to ensure an adequate flow of employees into jobs throughout the organization. The third views TM and talent as a generic good and resource, which can be managed to high performance (Lewis \& Heckman, 2006).

TM practices have a statistically higher significant impact on company attractiveness, the achievement of goals, customer satisfaction and corporate profit. Companies that adopt TM strategies which focus on succession planning enjoy a higher corporate profit and a higher trust and performance motivation, which they suggest could be an effect of talents being able to know their future career to a higher extent and seeing the integrity of the leaders. TM strategies focusing on the development of talents lead to an increased attractiveness of the employer, since talents usually want to know their career path possibilities, their opportunities for development and to have challenging assignments (Bethke-Langenegger et al., 2011).

TM is the activities and processes that involve the systematic identification of key positions which differentially contribute to the organization's sustainable competitive advantage, the development of a talent pool of high potential and high performing incumbents to fill these roles, and the development of a differentiated HR architecture to facilitate filling these positions with competent incumbents and to ensure their continued commitment to the organization (Collings \& Mellahi, 2009).

Organizations need to understand the costs and benefits of TM choices. The main risks for TM is to have a mismatch between the supply and demand of employees and their skills, and furthermore to risk talent development investments when failing to retain the employees. These risks stand in the way of making money through the business (Cappelli, 2008).

\subsection{Practical Implications}

Organizations that enjoy the highest economic performance consistently outperform their peers in three areas: TM, PM and rewards, and leadership development. These organizations use incentives to engage their managers in employee development, define talent more broadly and nurture their emerging potentials as well as attract internationals (Boston Consulting Group, 2007; 2008).

The organizations that excel at TM have implemented a system that is internally consistent and reinforce the practices they use to attract, select, develop, evaluate and retain talent; moreover, they align these practices with their business strategy, corporate culture and long term goals. TM system in place has many owners in the organization: the CEO, the managers at every level and the HR department (Beechler \& Woodward, 2009).

The managerial implications of TM processes can be utilized to enhance positive employee related outcomes, such as engagement and organizational commitment.

The HR as a function had gained more respect from the employees by having a systemic and professional process for conducting HR development in the organization. There are some risks related to the TM process, such as raising false expectations about career progression and increased internal competition. These are just some of the possible negative outcomes of "the war for talent" as asserted by Mellahi and Collings (2010).

\section{Limitations and Further Research}

The present research has certain limitations. First, the primary limitation is the scope and size of its sample. Second, the results from ECB might have been obtained if the study had included other banks

The paper should aid future research in the area of TM through (1) helping researchers to clarify the conceptual boundaries of TM, (2) providing a theoretical framework that could help researchers in framing their research efforts in the area, and (3) it aids managers in engaging with some of the issues they face with regard to TM.

This study opens the door for further research; (1) the strategies for successful implementation of TM could be used, (2) the relationship between employee engagement and OC should be tested, and (3) Can we plan the career of an employee through the TM? These areas are different in perspectives with very less or no research performed comparing the both. Therefore, a model from this perspective could be a better research opportunity. 


\section{Conclusion}

The study aimed at investigating the relationships between TM and SQ at the ECB. TM haves a significant impact on SQ.

TM remains relatively poorly defined and lacking in theoretical underpinning. The literature suggests that from a theoretical point of view, the area of TM is in its infancy and a significant degree of theoretical advancement is required. The contribution of this paper is two fold; to develop a clear and concise definition of TM, and propose a theoretical model of strategic TM.

The literature review investigated the way TM may be used to improve TM administration in an organization. A thorough plan process is a most for TM. Staff members must be cognizant of communication plans and the direction of the bank. Staff members must enjoy higher optimism and morale. TM must rely on talent planning and communication.

Selection must be comprehensive impartial to make good use of talents. Encouraging the talented employees needs developmental training and empowerment. Compensation and rewards should be optimally designed to attain pay incentives and indirect compensation/benefits, including flexible hours, family schemes etc.

PM measures achievement of the bank objectives. Employees liked the ECB appraisal system. Employee engagement and $\mathrm{OC}$ disclosed the fact that $\mathrm{OC}$ needed more improvement. The bank called for innovation and self evaluation.

Talents are not only confined within the organizations, they are also found outside the organization. These talented workforces have got their own career plan which the organization should realize.

If the proper talents are not arranged nor managed, any development task could face obstacles which may increase cost and time for the organization. TM should be viewed differently with better emphasis in the organizations- like software development companies, engineering firms, biotechnology related organizationswhere talents play a vital role. If compared in pragmatically and dynamical aspects, the classical role of the HRM is far less than the TM.

Merging both the career planning of an individual talented employee with the TM system of an organization could result in a better stimulus for that organization. Interestingly, all the people working in the organization may expect equal treatment as laid out by the organization itself. However, it would be a great challenge for the present HR departments to make reasons for special treatments of those "talents" under the same roof, along with the others-some of whom may have already worked for a longer time than the newly hired talented employee.

\section{References}

Aguinis, H., Gottfredson, R. K., \& Joo, H. (2012). Using performance management to win the talent war. Business Horizons, 55, 609-616. http://dx.doi.org/10.1016/j.bushor.2012.05.007

Ahlrichs, N. (2003). Manager of choice: Five competencies for cultivating top talent. California: Davies-Black.

Ananth, A., Ramesh, R., \& Prabaharan, B. (2011). Service quality GAP analysis in private sector banks: A customer perspective. Internationally Indexed Journal, II(1), 245-252.

Axelrod, B., Handeld-Jones, H., \& Michaels, E. (2002). A new game plan for c players. Harvard Business Review, January, 81-88.

Baumann, C. (2007). Predication of attitude and behavioral intentions in retail banking. Int. J. Bank. Mark., 25(2), 102-111. http://dx.doi.org/10.1108/02652320710728438

Becker, B. E., Huselid, M. A., \& Beatty, R. W. (2009). The differentiated workforce: Transforming talent into strategic impact. Boston, Mass: Harvard Business School Press.

Beechler, S., \& Woodward, I. C. (2009). The global "war for talent". Journal of International Management, 15, 273-285. http://dx.doi.org/10.1016/j.intman.2009.01.002

Berger, L., \& Berger, D. (2003). The talent management: Handbook creating organizational excellence by identifying, developing and promoting your best people. USA: McGraw-Hill.

Berry, L., Zeithaml, V., \& Parasuraman, A. (1988). The service quality puzzle. Business Horizons, 31(5), 35-43. http://dx.doi.org/10.1016/0007-6813(88)90053-5

Bethke-Langenegger, P., Mahler, P., \& Staffelbach, B. (2011). Effectiveness of talent management strategies. $\begin{array}{llll}\text { European Journal of International } & \text { Management, }\end{array}$ 
http://dx.doi.org/10.1504/EJIM.2011.042177

Blass, E. (2007). Talent management: Maximizing talent for future performance. London, UK: Chartered Management Institute.

Boston Consulting Group. (2007). The future of HR: Key challenges through 2015. Dusseldorf: Boston Consulting Group.

Boston Consulting Group. (2008). Creating people advantage. Boston, Mass: Boston Consulting Group.

Boudreau, J., \& Ramstad, P. (2007). Beyond HR: The new science of human capital. Boston, Massachusetts: Harvard Business School Press.

Brewster, C. L., Carely, P., Grobler, P., \& Holland, S. W. (2010). Contemporary issues in human resources management, gaining a competitive advantage (3rd ed.). Oxford Southern Africa.

Buckingham, M., \& Vosburgh, R. (2001). The $21^{\text {st }}$ century human resources function: It's the talent, stupid! Human Resource Planning, 24(4).

Cappelli, P. (2008). Talent management for the twenty-1st century. Harvard Business Review, March, 74-81.

Cartwright, R. (2003). Managing talent. United Kingdom, Capstone.

Caruana, A. (2002). Service loyalty: The effects of service quality and the mediating role of customer satisfaction. European Journal of Marketing, 36(7/8), 811-828. http://dx.doi.org/10.1108/03090560210430818

CIPD. (2007). Talent management. London, UK: Chartered Institute of Personnel and Development.

Clark, L. (2010). Talent management powered by Lominger. Lominger International, A Korn/Ferry Company, New York.

Coetsee, L. (2004). Peak performance and productivity: A practical guide for creation of a motivating climate (2nd ed.).

Coleman, A. (2005). Talent: A breed apart? Retrieved May 1, 2009, from http://www.managementissues.com/2006/8/24/research/talent-a-breed-apart-asp

Collings, D., \& Mellahi, K. (2009). Strategic talent management: A review and research agenda. Human Resource Management Review, 19(4), 304-313. http://dx.doi.org/10.1016/j.hrmr.2009.04.001

Cronin, J., \& Taylor, S. (1992). Measuring service quality: A reexamination and extension. Journal of Marketing, 56(3), 55-68. http://dx.doi.org/10.2307/1252296

Czepiel, J. (1990). Managing relationships with customers: A differentiation philosophy of marketing. In D. E. Bowen, R. B. Chase \& T. G. Cummings (Eds.), Service management effectiveness (pp. 299-323). San Francisco: Jossey-Bass.

Daniel, W. (1999). Biostatistics: A foundation for analysis in the health sciences (7th ed.). New York: John Wiley $\&$ Sons.

Davis, G., Yoo, M., \& Baker, W. (2003). The small world of the American corporate elite, 1982-2001. Strategic Organization, 1(3), 301-326. http://dx.doi.org/10.1177/14761270030013002

DuBrin, A. (2005). Fundamentals of organizational behavior. Canada: Thomson South-Western.

DuBrin, A. (2010). Principles of leadership (6th ed.). Canada: South-Western Cengage-Learning.

Eshghi, A., Roy, S., \& Ganguli, S. (2008). Service quality and customer satisfaction: An empirical investigation in Indian mobile telecommunications services. Marketing Management Journal, 18(2), 119-144.

Fishman, C. (1998). The war for talent. Fast Company, August, 104-106.

Frank, F., Finnegan, R., \& Taylor, C. (2004). The race for talent: Retaining and engaging workers in the $21^{\text {st }}$ century. Human Resource Planning, 27(3), 12-25.

Gakovic, A., \& Yardley, K. (2007). Global talent management at HSBC. Organization Development Journal, 25(2), 201-205.

Gebelein, S. (2006). Talent management: Today's HR departments do much more than just hiring and firing. Personnel Decisions International. Minnesota Business Magazine.

Gomez-Mejia Luis, R., Balkin, D. B., \& Robert, L. C. (2004). Managing human resources (4th ed.). USA: Prentice Hall. 
Gracia, E., Salanova, M., Grau, R., \& Cifre, E. (2013). How to enhance service quality through organizational facilitators, collective work engagement, and relational service competence. European Journal of Work and Organizational Psychology, 22(1), 42-55. http://dx.doi.org/10.1080/1359432X.2011.628793

Heinen, J. S., \& O'Neill, C. (2004). Managing talent to maximize performance. Employment Relations Today, 31(2), 67-82. http://dx.doi.org/10.1002/ert.20018

Höglund, M. (2012). Quid pro quo? Examining talent management through the lens of psychological contracts. Personnel Review, 419(2), 126-142. http://dx.doi.org/10.1108/00483481211199991

Hughes, J., \& Rog, E. (2008). Talent management: A strategy for improving employee recruitment, retention and engagement within hospitality organizations. International Journal of Contemporary Hospitality Management, 20(7), 734-757.

Huselid, M. A., Jackson, S. E., \& Schuler, R. S. (1997). Technical and strategic human resource management effectiveness determinates of firm performance. Academy of Management Journal, 40, 171-188. http://dx.doi.org/10.2307/257025

Kirkland, S. (2009). Compensation plans that pay. Journal for Management, 5(2), $22-23$.

Knez, M., Ruse, D. H., Kochanski, J. T., \& Ledford, G. E. (2004). Optimizing your investment in your employees. In L. Berger \& Berger, D. (Eds.), Talent management handbook. New York: McGraw-Hill.

Kock, R., \& McNamara, K. (2009). Are your employees engaged: Findings from a pilot survey of South African organizations. Retrieved 19 March, 2010, from http://www.hrpractice.co.za

Kumar, M., Kee, F., \& Manshor, A. (2009). Determining the relative importance of critical factors in delivering service quality of banks: An application of dominance analysis in SERVQUAL model. Managing Service Quality, 19(2), 211-228. http://dx.doi.org/10.1108/09604520910943198

Lewis, R. E., \& Heckman, R. J. (2006). Talent management: A critical review. Human Resource Management Review, 16, 139-154. http://dx.doi.org/10.1016/j.hrmr.2006.03.001

Lymperopoulos, C., Chaniotakis, I. E., \& Soureli, M. (2006). The importance of service quality in bank selection for mortgage loans. Managing Service Quality, 16(4), 365-379. http://dx.doi.org/10.1108/09604520610675702

McDonnell, A. (2011). Still fighting the "war for talent"? Bridging the science versus practice gap. Journal of Business Psychology, 26, 169-173. http://dx.doi.org/10.1007/s10869-011-9220-y

Mellahi, K., \& Collings, D. G. (2010). The barriers to effective global talent management: The example of corporate elites in MNEs. Journal of World Business, 45(2), 143-149. http://dx.doi.org/10.1016/j.jwb.2009.09.018

Michaels, E., Handfield-Jones, H., \& Axelrod, B. (2001). The war for talent. United States of America: McKinsey \& Company, Inc.

Miller, C. C., Burke, L. M., \& Glick, W. H. (1998). Cognitive diversity among upper-echelon executives: Implications for strategic decision processes. Strategic Management Journal, 19, 39-58. http://dx.doi.org/10.1002/(SICI)1097-0266(199801)19:1<39::AID-SMJ932>3.0.CO;2-A

Munusamy, J., Chelliah, S., \& Mun, H. (2010). Service quality delivery and its impact on customer satisfaction in the banking sector in Malaysia. International Journal of Innovation, Management and Technology, 1(4), 398-404.

Nelson, K., \& McCann, J. E. (2008). Designing for knowledge worker retention \& organization performance. Journal of Management and Marketing Research. Retrieved from http://www.aabri.com/manuscripts/09272.pdf

Newhouse, N., Lewis, B., \& Jones, J. W. (2004). Strategic talent management: Assessments as a foundation. Presented at the Annual Conference of the Society for Personality Assessment, Miami, FL, March 11.

Osman, I., Berbary, L., Sidani, Y., Al-Ayoubi, B., \& Emrouznejad, A. (2011). Data envelopment analyses model for the appraisal and relative performance evaluation of nurses at an intensive care unit. Journal of Medical Systems, 35(5), 1039-1062. http://dx.doi.org/10.1007/s10916-010-9570-4

Oxford Dictionaries. (2012). Definition of talent, natural, aptitude. Retrieved from http://oxforddictionaries.com/

Parasurman, A., Zeithaml, V., \& Berry, L. (1985). A conceptual model of service quality and its implications for future research. Journal of Marketing, 49, 41-50. http://dx.doi.org/10.2307/1251430 
Parasurman, A., Zeithaml, V., \& Berry, L. (1988). SERVQUAL: A multi- item scale for measuring consumer perceptions of service quality. Journal of Retailing, 64(1), 12-40.

Phillips, J., \& Connell, A. (2003). Managing employee retention: A strategic accountability approach. Burlington: Butterworth-Heinemann.

Popescu, C., Avram, R., \& Dana, M. (2012). New trends in human resource management in the hospitality industry. Proceedings of the Scientific Conference AFASES, pp. 185-190.

Richman, L., Janet, T., Laurie, L., Shannona, E., \& Robert, T. (2008). The relationship of perceived flexibility, supportive work-life policies and use of formal flexibility arrangements and occasional flexibility to employee engagement and expected retention. Journal of Community, Work \& Family, 22(2), 183-187. http://dx.doi.org/10.1080/13668800802050350

Ritz, A., \& Sinelli, P. (2010). Talent management. In A. Ritz \& N. Thom (Eds.), Talent Management (pp. 1-23). Wiesbaden: Gabler. http://dx.doi.org/10.1007/978-3-8349-8584-2

Sadek, D., Zainal, N., Taher, M., \& Yahya, A. (2010). Service quality perceptions between cooperative and Islamic banks of Britain. American Journal of Economics and Business Administration, 2(1), 1-5. http://dx.doi.org/10.3844/ajebasp.2010.1.5

Schaufeli, W. B., Salanova, M., Gonzáles-Romá, V., \& Bakker, A. B. (2002). The measurement of engagement and burnout: A confirmatory factor analytic approach. Journal of Happiness Studies, 3, 71-92. http://dx.doi.org/10.1023/A:1015630930326

Scott, B., \& Revis, S. (2008). Talent management in hospitality: Graduate career success and strategies. International Journal of Contemporary Hospitality Management, 20(7), 781-791. http://dx.doi.org/10.1108/09596110810897600

Shukla, R. (2009). Talent management: Process of developing and integrating skilled workers. Global Indian Publication Pvt. Ltd.

Silzer, R., \& Dowell, B. E. (2010). Strategic talent management matters. In R. Silzer \& B. E. Dowell (Eds.), Strategy-driven talent management (pp. 3-72). San Francisco: John Wiley \& Sons.

Tansley, C. (2011). What do we mean by the term "talent" in talent management? Industrial and Commercial Training, 43(5), 66-274. http://dx.doi.org/10.1108/00197851111145853

Tansley, C., Turner, P. A., Foster, C., Harris, L. M., Stewart, J., \& Sempik, A. (2007). Talent: Strategy, management, measurement. Plymouth: Chartred Institute of Personal \& Development.

Vaiman, V., \& Vance, C. M. (2008). Smart talent management. Cheltenham: Edward Elgar Publishing. http://dx.doi.org/10.4337/9781848442986

Wagner Sue Ellen. (2006). Satisfied to engaged. Nursing Management Journal, (25). Retrieved from http://www.dirjournal.com/guides/motivating-your-staff

Wikström, C., \& Martin, H. (2012). Talent management Praktiken. Stockholm: Ekerlids Förlag.

Yarnall, J. (2011). Maximising the effectiveness of talent Pools: A review of case study literature. Leadership and Organization Development Journal, 32(5), 510-526. http://dx.doi.org/10.1108/01437731111146596

Zeithaml, V. (2000). Service quality, profitability and the economic worth of customers: What we know and what we need to learn. Journal of the Academy of Marketing Science, 28(1), 67-85. http://dx.doi.org/10.1177/0092070300281007

Zheng, C. (2009). Keeping talents for advancing service films in Asia. Journal of Service Management, 20(5), 482-502. http://dx.doi.org/10.1108/09564230910995107

Zikmund, W. (2000). Business research methods (6th ed.). Florida: Harcourt College Publishers.

\section{Copyrights}

Copyright for this article is retained by the author(s), with first publication rights granted to the journal.

This is an open-access article distributed under the terms and conditions of the Creative Commons Attribution license (http://creativecommons.org/licenses/by/3.0/). 